\title{
Aminopterin Sodium
}

National Cancer Institute

\section{Source}

National Cancer Institute. Aminopterin Sodium. NCI Thesaurus. Code C74554.

The sodium salt of a pterin derivative with antineoplastic and immunosuppressive properties. As a folate analogue, aminopterin competes for the folate binding site of the enzyme dihydrofolate reductase, thereby blocking tetrahydrofolate synthesis, and resulting in depletion of nucleotide precursors and inhibition of DNA, RNA and protein synthesis. ( $\mathrm{NCl04})$ 